\title{
SAUMADE Frédéric, Maçatl. Les transformations mexicaines des jeux taurins
}

\section{Virginie Baby-Collin}

\section{OpenEdition}

\section{Journals}

Édition électronique

URL : http://journals.openedition.org/jsa/11781

DOI : 10.4000/jsa.11781

ISSN : 1957-7842

\section{Éditeur}

Société des américanistes

\section{Édition imprimée}

Date de publication : 5 octobre 2011

Pagination : 331-334

ISSN : 0037-9174

\section{Référence électronique}

Virginie Baby-Collin, " SAUMADE Frédéric, Maçatl. Les transformations mexicaines des jeux taurins »,

Journal de la Société des américanistes [En ligne], 97-1 | 2011, mis en ligne le 10 juillet 2011, consulté le 23 septembre 2020. URL : http://journals.openedition.org/jsa/11781; DOI : https://doi.org/10.4000/ jsa. 11781

Ce document a été généré automatiquement le 23 septembre 2020

(c) Société des Américanistes 


\title{
SAUMADE Frédéric, Maçatl. Les transformations mexicaines des jeux taurins
}

\author{
Virginie Baby-Collin
}

\section{RÉFÉRENCE}

SAUMADE Frédéric, Maçatl. Les transformations mexicaines des jeux taurins, Presses universitaires de Bordeaux, coll. « Corps de l'esprit », Bordeaux, 2008, 395 p.

1 Plonger dans le livre de Frédéric Saumade est un voyage qui requiert curiosité et confiance : le lecteur doit accepter de suivre, à l'issue d'une introduction qui ne délivre pas les clés, les détours d'une aventure humaine qui commence par la marche de l'ethnologue en quête de jeux taurins dans le vacarme de l'avenue Constituyentes de Mexico. Le titre, Maçatl, reste longtemps mystérieux à la lecture et le sous-titre, Les transformations mexicaines des jeux taurins, est infiniment modeste au regard de l'ambition de l'ouvrage. Car, au prisme des jeux taurins, il s'agit de relire la construction du métissage, socle fondamental de la société mexicaine, et de réinterpréter le choc de la conquête hispanique $\mathrm{du} \mathrm{XvI}^{\mathrm{e}}$ siècle : « dans le métissage, estce vraiment le pouvoir blanc qui "colonise l'imaginaire", ou ne serait-ce pas au contraire la vision mésoaméricaine du monde qui vampirise, en quelque sorte, la civilisation hispano-européenne en l'immergeant dans la complexité des représentations nées du contact?» (p.9).

2 La portée et l'intérêt de l'ouvrage vont évidemment bien au-delà du public féru de bestiaires, de corridas, de spectacles équestres, de mises en scène festives ou diaboliques de l'animalité : ce travail interpelle le chercheur en sciences humaines par sa réinterprétation passionnante de la Mésoamérique, espace de continuités spatiales et temporelles qui a su intégrer les ruptures et les résoudre dans d'incessantes ambiguïtés matérielles et symboliques auxquelles l'auteur s'attelle. 
3 Frédéric Saumade part de l'observation de la surface, des scènes, des individus, des paysages, d'un tableau géographique et d'une photographie de la fête, pour plonger ensuite dans l'analyse de sa portée heuristique, tout en assumant une première personne mise en scène dans ses aventures parfois cocasses. La qualité de l'édition des Presses universitaires de Bordeaux enrichit l'ouvrage de deux cahiers photographiques en couleurs qui mettent très utilement en image les jeux et symboles équestres et taurins du récit ainsi que leurs protagonistes.

4 L'ouvrage s'ouvre sur une ethnographie fine de deux univers contrastés : celui de la charreada, sophistiqué, urbain, élitiste, sport de la haute société métissée faisant état d'une grande maîtrise technique et adapté de la corrida à laquelle l'auteur s'est intéressé dans ses précédents ouvrages; celui de l'univers du jaripeo, sorte de rodéo mexicain réservé aux mauvais garçons, défi jeté à la mort dans les arènes populaires, où le cheval est absent et le taureau monté comme il le peut par le jinete. La mise en regard de ces deux pratiques de jeux taurins ouvre une réflexion sur le métissage de pratiques moins opposées qu'il n'y parait, valorisant paradoxalement la bâtardise et la distance aux origines hispaniques, dans des cadres de reproduction sociale qui pourtant s'opposent. L'analyse des jeux entre homme, cheval et taureau, montant/monté, attachant/attaché, se poursuit dans un monde rural et festif : celui de carnavals, fêtes patronales et jeux d'arènes villageois, dans la région altiplanique au nord-est de Mexico, aux confins de Tlaxcala et de Puebla où s'est situé l'essentiel de la recherche de terrain. Les figures taurines y sont mises en scène par des masques et des déguisements variés, dans des contextes otomi, nahua ou métissés. Le récit permet la rencontre de différents acteurs: mayordomo qui encadre l'organisation des festivités, types de danseurs et de musiciens, jeunes costumés en vieillards ou huehue dans les villages otomi, hommes et femmes dont les tâches et les symboles associés sont sexuellement différenciés, mais reliés par le rite du torito et le symbole phallique du mât, qui contribuent à fonder l'identité communautaire d'un quartier.

5 Frédéric Saumade revisite de façon passionnante Santa Ana Hueytlalpan, étudié dans les années 1970 par Jacques Galinier, village situé sur une route à grande circulation, dans un contexte où les hommes migrent saisonnièrement non plus seulement vers les terres chaudes et caféières du Veracruz, mais aussi vers les États-Unis. Les changements opérés dans le carnaval local, dans ce contexte d'interconnexion croissante de la société villageoise avec le monde extérieur, ne sont ici pas lus comme une perte de l'authenticité de la tradition: le contact est un élément dynamique qui maintient la pertinence d'une cosmogonie originale, en accommodant la fête aux évolutions de l'environnement. La confrontation entre culture locale et histoire contemporaine, par le biais des migrations, permet, via le carnaval, de recréer un système spatial traditionnel, de régénérer une représentation cyclique du temps social inscrit dans la cosmogonie otomi.

6 L'étude des folklores va ainsi au-delà d'un schème d'acculturation, montrant comment l'expression du métissage réactive un ordre symbolique conforme aux traditions préhispaniques: les contacts entre communautés et extérieur renforcent l'unité des espaces locaux, si bien que «la force de la culture populaire mexicaine revient à convertir une situation d'altération quasi permanente en un facteur d'identification qui opère dans [...] la "conscience collective" » (p. 245). La médiation européenne apparaît alors comme un élément incontournable de ces pratiques symboliques. 
7 Moins systématiquement construite selon le schéma ethnographie située/analyse interprétative que les deux premières, la dernière partie de l'ouvrage s'intéresse aux liens entre culture matérielle et symbolique: elle montre comment se construit une pensée mésoaméricaine qui passe par un usage alternatif des catégories imposées par l'impérialisme occidental et la Conquête. Les relations symboliques (oppositions, transitions, médiations) entre bestiaires à cornes, à pattes, à plumes, volants ou terrestres sont analysées grâce aux dualités entre animaux de rente et animaux de loisirs, entre sauvage et domestique: dindon domestique préhispanique versus coq de combat; oiseaux de terre versus oiseaux de haut vol. Les usages matériels des animaux et leurs représentations sont relus sur le plan symbolique. L'ethnozoologie glisse vers l'ethnobotanique, dans le contexte géographique spécifique que constitue la Mésoamérique. La corde d'ixtle, utilisée dans les jeux taurins, faite de maguey, permet d'exprimer les liens symboliques qui opposent et unissent le maïs, plante nourricière par excellence de cet espace mésoaméricain, et le maguey ou l'agave, ingrédient du pulque/mezcal/tequila, deux plantes qui renvoient à l'humide (maïs) et au sec (maguey), caractéristiques essentielles de l'espace-temps mexicain, rythmé par l'alternance de la saison des pluies et de la saison sèche et articulé par les échanges entre terres plus sèches au nord et plus humides au sud. Ce sont ces espaces que la Mésoamérique réconcilie et constitue.

8 Au cœur de ces translations et oppositions symboliques, le titre se résout: Maçatl, à la fois cerf et cheval nahuatl, est aussi symboliquement bœuf, et est cornu comme lui. Cerf sauvage, cheval et bœuf domestiques importés par la colonisation et au centre des jeux taurins, forment ainsi une trilogie que Maçatl concilie tout en exprimant les dualismes antagoniques qui les opposent.

Une relecture des récits de la Conquête, émanant d'historiens, chroniqueurs et témoins, permet de puiser enfin dans la confrontation des textes pour comprendre les fondements des mythes. La place particulière de Cortés dans l'historiographie mexicaine, «l'Indien Cortés », est révélée par son statut intermédiaire entre homme et femme (on l'appelle aussi la Malinche), autochtone et étranger (il est la réincarnation du dieu Serpent à plumes Quetzalcóatl), humain et animal (lui et sa monture). On y rejoint la thèse de l'auteur d'une ingestion de l'Européen dans la cosmogonie indigène.

10 Le travail minutieux d'analyse ethnologique, des univers équestres et taurins à leur mise en scène festive, puis des univers ethnozoologiques et ethnobotaniques à la relecture des textes historiques de la Conquête, permet à Frédéric Saumade d'affirmer la relativisation forte de la supposée rupture créée par la colonisation. Détournant le projet colonial, la culture mésoaméricaine métisse crée en effet un univers ambigu de dialogues entre mythe, réalité et imaginaire, mis au service des civilisations indigènes. Plus qu'une rupture, il y a ainsi permanence d'une "structure lourde, au sens braudélien du terme, qui amalgame les civilisations dans la longue durée comme s'il s'agissait de couches géologiques» (p.371), laissant apparaître des univers en recomposition, capables de «s'approprier l'altérité pour en faire la condition sine qua non de l'identité » (p.376). Loin d'une idéalisation de l'indianité précoloniale, loin d'un essentialisme indigéniste, la perspective de Frédéric Saumade questionne la thèse d'une rupture traumatique, montrant comment elle fut intégrée dans la vision du monde des vaincus de 1521 et dans leur représentation cyclique et eschatologique du temps.

11 Profondément original par son entrée par l'animalité et les jeux taurins, perspective dont la fécondité anthropologique est amplement démontrée par la qualité de 
l'ouvrage, Maçatl offre donc un regard passionnant sur le métissage mésoaméricain, qui vient compléter les interprétations existantes tout en ouvrant des pistes de recherches fascinantes, de l'ethnobotanique à l'ethnozoologie.

\section{AUTEURS}

\section{VIRGINIE BABY-COLLIN}

Université de Provence 